\title{
GENES CONTROLLING CHIASMA FREQUENCY IN HORDEUM
}

\author{
M. D. GALE and H. REES \\ Department of Agricultural Botony, University College of Wales, Aberystwyth
}

Received 14.x.69

\section{INTRODUCTION}

THE following is an account of variation in chiasma frequency at meiosis within the genus Hordeum. Small but significant differences in chiasma frequencies between five Hordeum subspecies are shown to be genotypically controlled. Comparisons between parents, their hybrids and derivatives provide information about the nature of the gene systems controlling the variation. By means of " morphological " markers, an assay of the chromosome complement was also carried out in order to locate genes that control the chiasma frequency variation.

\section{Materials AND Methods}

\section{a. The Subspecies}

The five subspecies used, all diploids with $2 n=14$, are listed in table 1 . Crosses between all five are easily accomplished and produce fully fertile

TABLE 1

The five Hordeum subspecies

Hordeum agriocrithon
H. spontaneum (vulgare,
$\quad$ ss. spontaneum)
H. hexastichum
H. distichum
H. intermedium

ex. R. Davies, Welsh Plant Breeding Station ex. Dr W. Bowden, Ottawa

from D. B. James, Agricultural Botany Department, University College of Wales, Aberystwyth

offspring. The interfertility, amongst other things, has led to the view that the five forms merit subspecific rather than the specific rank previously accorded (see Bell, 1965; A berg, 1940). Custom and tradition and, perhaps, convenience account for the retention of specific nomenclature.

\section{b. The Method}

Experimental design. In 1966 seeds from a diallel cross, comprising the five parents and $F_{1}$ reciprocals, were sown eight to a pot in two replicates. The randomised pots were kept in a greenhouse for six weeks and then transferred outdoors. Heads were fixed for cytological examination from two plants of each genotype in each replicate.

In 1967 the seed from the reciprocal $F_{2}$ 's were pooled because no reciprocal differences were revealed by analysis of the $F_{1}$ results. Seeds from this "half diallel ", comprising parents and $\mathrm{F}_{2}$, were sown in two-inch pots, kept in a warm greenhouse for two weeks and then transplanted into the field. The lay-out comprised eight blocks $(\mathrm{A}-\mathrm{H})$ each containing two randomised 
plots of each parent and $\mathrm{F}_{2}$ families. Each plot contained a row of five plants at one-foot intervals, two feet between rows, the whole experiment surrounded by a guard row. Heads were fixed in each of two plants in each family in blocks A-D.

Cytological. The heads were fixed in Carnoy's fluid and staining was by aceto-carmine. The chiasma frequency per plant was expressed as the mean of 20 pollen mother cells, scored at first metaphase.

Morphological. The 600 plants comprising blocks A-D in 1967 were classified in respect of the eleven characters below:

(i) Shattering capacity.

(ii) DDT resistance.

(iii) Height.

(iv) Intermedium head type.

(v) Rachilla hair type.

(vi) Seed colour.

(vii) Tiller number.

(viii) Kernel row number.

(ix) Glum-awn length.

(x) Awn length.

(xi) Spike density (spike internode length).

Whereas the genes controlling some of the characters are well mapped there is controversy and disagreement about the number, the action and location of genes controlling others. For some, also, the classification of phenotypes is by no means straightforward. For these reasons it is necessary to explain, in some detail, the methods adopted for scoring and the nature of the segregations encountered in the present material.

\section{(i) Shattering capacity}

Brittle rachis or "shattering" genes are a feature of wild and primitive barleys. Most workers (e.g. Takahashi, 1955) attribute control to two genes, $B t_{2}$ or $B t_{3}$ and $B t$, which are complementary and situated on chromosomes 3 and 5 respectively. The results of the present work agree with this interpretation, i.e. control by two independent complemenatary loci, giving a 9 brittle : 7 non-brittle $\mathrm{F}_{2}$ ratio.

\section{(ii) $D D T$ resistance}

Resistance to DDT is controlled by a single recessive gene (ddt) located on or near the satellite of chromosome 7 (Hayes and Rana, 1966). This character was scored by spraying green leaves with a 0.2 per cent. solution of Strykol DDT, marking them with a paper tab and inspecting them after ten days for unnatural yellowing. Although plants in blocks A-D did not give a clear 3 susceptible : 1 resistant $F_{2}$ ratio, blocks $E-H$ gave such a ratio when sprayed as whole plants. An excess of resistant plants in blocks A-D was presumably due to misclassification of leaves not sufficiently wetted by the spray.

\section{(iii) Height}

Plant height in barley is generally treated as a very complex character much influenced by the environment and consequently displaying low 
heritability (e.g. Jogi, 1956). At least part of the variation would appear to be governed by the " $H$ " locus on chromosome 2 (Mann, 1953). In the present work height was treated as a continuous variable, no attempt being made to split the phenotypes into arbitrary, and dubious, tall and short classes.

\section{(iv) Intermedium head type}

This type of spike is shown by $H$. intermedium, a subspecies with awnless fertile lateral florets. The $I^{h}$ allele on chromosome 4 governs the production of these fertile laterals in the presence of the $V$ allele for two-rowed spike type (Murty and Jain, 1960).

\section{(v) Rachilla hair type}

Short rachilla hairs are determined by a recessive allele on chromosome 7 (Doney, 1961). The two rachilla types were easily distinguishable and the $F_{2}$ ratio fitted a 3 long : 1 short segregation.

\section{(vi) Seed colour}

Black, as opposed to non-black, lemma and pericarp is reported by most workers (e.g. Litzenburger and Green, 1951) to be due to a single gene difference with "black" dominant over " non-black" types. The gene " $b$ " is carried on chromosome 5. Das (1957), however, reported a twofactor mode of inheritance. Results obtained in the present work show a monofactorial type of inheritance.

\section{(vii) Tiller number}

Genetic control of tiller number has been established by Murty and Jain (1960). They found correlations between tiller number and segregation at the $\mathcal{N} / n$ locus (hulled/naked grain) on chromosome 1. In the present work, tiller number has been treated as a continuous variable.

\section{(viii) Kernel row number}

Kernel row number is determined mainly by the $V / v$ locus on chromosome 2 but there are modifying loci such as the $I / i$ locus on chromosome 4 (Woodward, 1949). Crosses with $H$. hexastichum as the six-rowed parent gave $\mathbf{F}_{2}$ progenies with $3: 1$ segregations. Crosses with $H$. agriocrithon as the sixrowed parent gave, on the other hand, ratios of $15: 1$ non six-rowed to sixrowed, the non six-rowed class including intermediate as well as two-rowed phenotypes. Although two genes are clearly involved, the precise basis of the control is not clear from the data available.

\section{(ix) Glume-awn length}

In the present work segregating $\mathrm{F}_{2}$ 's gave a ratio of three long to one short awn. This character is controlled by the $E_{2} / e_{2}$ locus on chromosome 1 (Doney, 1961).

\section{(x) Awn length}

Segregating $\mathrm{F}_{2}$ 's gave good 3:1 short and intermediate to long awns ( $c f$. Takahashi et al., 1953). A gene controlling awn length, $l k 5$, has been 
mapped in chromosome 2 (see Litzenburger and Green, 1951 ; and Woodward, 1957). Whereas the long awned phenotypes were fairly easily identified the short and intermediate forms were not. Consequently, for correlation purposes, the awn length character was treated as a continuous variable.

\section{(xi) Spike density (spike internode length)}

Reports differ concerning the inheritance of this character, much confusion arising from the pleiotropic effects of the genes for spike density on the length of the spike, internode number and length of the coleoptile (Takahashi, 1951). Litzenburger and Green (1951) found the character to be inherited monofactorially with lax dominant over dense spike. The gene, Rin/rin, affecting spike density, was located on chromosome 2 by Woodward (1957). Aziz and Mir (1960) say that more than one gene may be involved.

In the present work, although lax tends to be dominant over dense spike, no clear cut segregation was observed and the character has been treated as a continuous variable, classified on the basis of spike internode length.

The analyses. These fall into two groups. The first is concerned with partitioning the heritable variation in chiasma frequency into its component parts viz. into additive and non-additive variation. The analyses consist of classical biometrical methods developed by Jinks (1954) and Morley-Jones (1965).

The purpose of the second type of analysis was to assay the chromosome complement for genes controlling the chiasma frequency variation. Essentially, the assay depends on establishing correlations between differences in chiasma frequency and the segregation of the marker genes located on different chromosomes. Details follow in the next section.

\section{REsults}

Table 2 gives the mean chiasma frequencies for the parent, $F_{1}$ and $F_{2}$ families. As mentioned earlier there was no significant difference between reciprocals of the $F_{1}$ families sown in 1966. For this reason the values from reciprocals were pooled in table 2 and only a " half diallel " carried forward to the $F_{2}$.

\section{(i) Parents}

An analysis of variance of the means of subspecies over two seasons appears in table 3 . This table shows:

(a) There is a highly significant difference between subspecies $(P=<0.001)$.

(b) There is a significant variation due to seasons $(P=0.05-0.01)$.

(c) The difference between seasons is independent of the genotype, as indicated by the insignificant mean square for interaction.

The cause of the seasonal difference is not known. It could be due to a difference in temperature (e.g. Dowrick, 1957; Henderson, 1962) or even in soil fertility (see Law, 1963).

The variation between subspecies is attributed to genotypic control as distinct from structural differences between chromosomes. The grounds for this conclusion are that $F_{1}$ hybrids and their $F_{2}$ derivatives show no sign whatever of structural heterozygosity. The conclusion is amply confirmed by the results of the assay described in a later section. 
TABLE 2

The mean chiasma frequencies of parent and $F_{1}$ families (1966) and of parent and $F_{2}$ families (1967). 1966 results from four plants of each genotype, 1967 results from eight plants of each genotype except for $1 \times 2$ (five plants) and $2 \times 5$ (four plants)

\begin{tabular}{|c|c|c|c|c|c|c|c|}
\hline & Subspecies & 1 & 2 & 3 & 4 & 5 & Array totals \\
\hline 1966\{ & $\begin{array}{l}\text { 1. H. agriocrithon } \\
\text { 2. H. spontaneum } \\
\text { 3. H. hexastichum } \\
\text { 4. H. distichum } \\
\text { 5. H. intermedium }\end{array}$ & $14 \cdot 50$ & $\begin{array}{l}14 \cdot 13 \\
13 \cdot 88\end{array}$ & $\begin{array}{l}14 \cdot 30 \\
13 \cdot 82 \\
13 \cdot 78\end{array}$ & $\begin{array}{l}14 \cdot 42 \\
14 \cdot 18 \\
14 \cdot 07 \\
14 \cdot 00\end{array}$ & $\begin{array}{l}14 \cdot 30 \\
13 \cdot 87 \\
14 \cdot 00 \\
13 \cdot 95 \\
14 \cdot 13\end{array}$ & $\begin{array}{l}71 \cdot 65 \\
69 \cdot 88 \\
69 \cdot 97 \\
70 \cdot 62 \\
70 \cdot 25\end{array}$ \\
\hline 1967\{ & $\begin{array}{l}\text { 1. H. agriocrithon } \\
\text { 2. H. spontaneum } \\
\text { 3. H. hexastichum } \\
\text { 4. H. distichum } \\
\text { 5. H. intermedium }\end{array}$ & $15 \cdot 64$ & $\begin{array}{l}14 \cdot 61 \\
13 \cdot 62\end{array}$ & $\begin{array}{l}14 \cdot 85 \\
14 \cdot 08 \\
14 \cdot 19\end{array}$ & $\begin{array}{l}15 \cdot 28 \\
14 \cdot 39 \\
14 \cdot 68 \\
14 \cdot 33\end{array}$ & $\begin{array}{l}14 \cdot 26 \\
14 \cdot 74 \\
14 \cdot 24 \\
14 \cdot 44 \\
14 \cdot 14\end{array}$ & $\begin{array}{l}74 \cdot 64 \\
71 \cdot 44 \\
72 \cdot 04 \\
73 \cdot 12 \\
71 \cdot 82\end{array}$ \\
\hline
\end{tabular}

TABLE 3

An analysis of variance of the chiasma frequencies of the parental subspecies grown in 1966 and 1967

\begin{tabular}{lrrrrr}
\multicolumn{1}{c}{ Item } & d.f. & S.S. & M.S. & V.R. & P. \\
Subspecies & $\mathbf{4}$ & 16.40 & $4 \cdot 10$ & 13.66 & $<0 \cdot 001$ \\
Years & 1 & 1.43 & $1 \cdot 43$ & $4 \cdot 77$ & $0 \cdot 05-0 \cdot 01$ \\
$S \times \Upsilon$ & $\mathbf{4}$ & 2.94 & $0 \cdot 74$ & $2 \cdot 45$ & \\
Error & 50 & $15 \cdot 00$ & 0.30 & &
\end{tabular}

TABLE 4

The "half-diallel" analysis of variance; parents and $F_{1}$

\begin{tabular}{|c|c|c|c|c|c|}
\hline Item & d.f. & S.S. & M.S. & V.R. & P. \\
\hline$a$ & 4 & 0.5509 & $0 \cdot 1877$ & $21 \cdot 85$ & $<0.001$ \\
\hline$b$ & 10 & $0 \cdot 1233$ & 0.0123 & 1.95 & 0.05 \\
\hline$b_{1}$ & 1 & 0.0071 & 0.0071 & $1 \cdot 31$ & \\
\hline$b_{2}$ & 4 & 0.0594 & 0.0149 & $2 \cdot 37$ & $0 \cdot 10-0 \cdot 05$ \\
\hline$b_{\mathrm{s}}$ & 5 & 0.0568 & 0.0114 & $1 \cdot 81$ & \\
\hline error & 45 & 0.2835 & 0.0064 & & \\
\hline
\end{tabular}

TABLE 5

The "half-diallel" analysis of variance; parents and $F_{2}$

\begin{tabular}{|c|c|c|c|c|c|}
\hline Item & d.f. & S.S. & M.S. & V.R. & P. \\
\hline$a$ & 4 & $2 \cdot 3427$ & 0.5857 & $8 \cdot 72$ & $<0.001$ \\
\hline$b$ & 10 & $1 \cdot 1362$ & 0.1136 & 1.69 & $0 \cdot 10-0.05$ \\
\hline$b_{1}$ & 1 & 0.0998 & $0 \cdot 0998$ & 1.49 & \\
\hline$b_{2}$ & 4 & 0.4258 & $0 \cdot 1064$ & $1 \cdot 58$ & \\
\hline$b_{3}$ & 5 & 0.6106 & 0.1221 & $1 \cdot 82$ & \\
\hline error & 98 & 6.5856 & 0.0672 & & \\
\hline
\end{tabular}

(ii) Diallels

Analyses of Variance. The half diallel analyses presented in tables 4 and 5 are derived from Morley-Jones (1965) based on a genetical model by Hayman (1954). The " $a$ " item relates to additive effects and " $b$ " to 

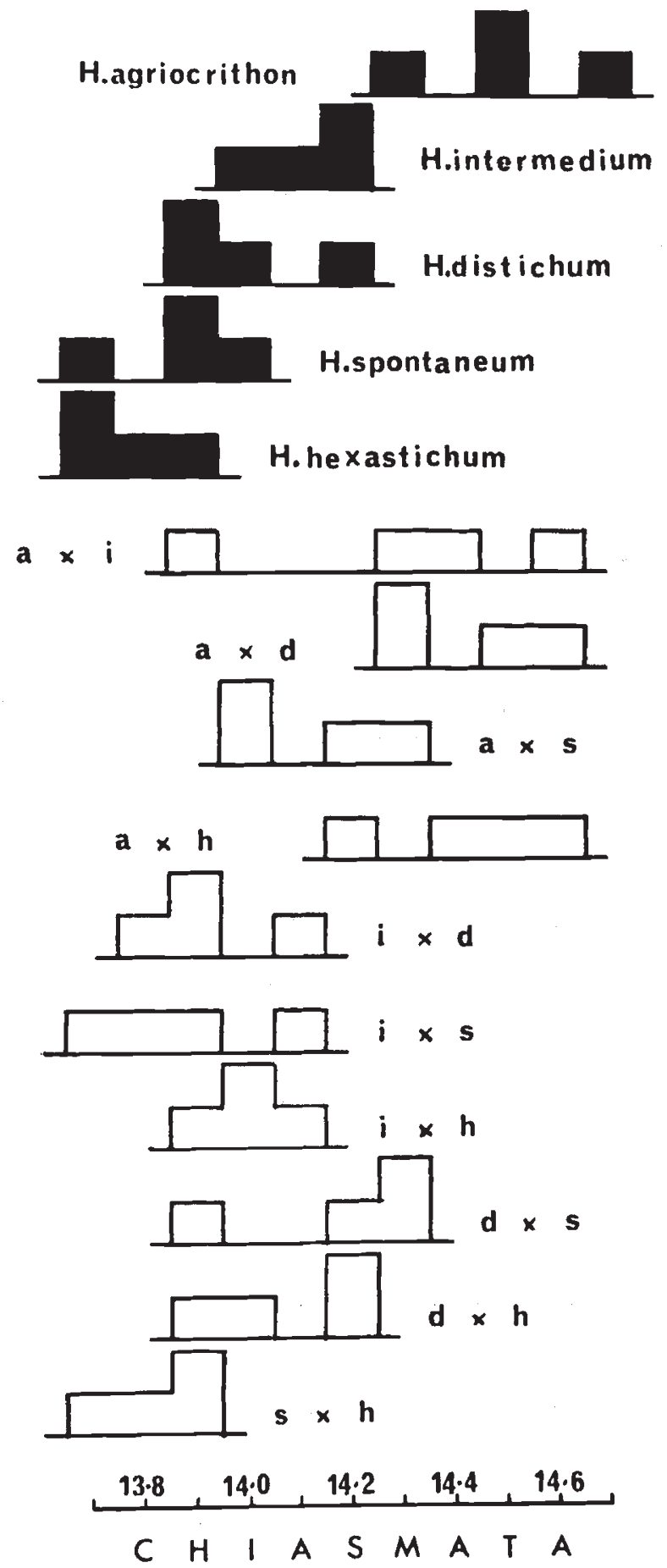

FIG. 1.-The chiasma frequency distribution in the Hordeum subspecies and their $F_{1}$ hybrids. 
total non-additive effects. If we assume no non-allelic interaction, a reasonable assumption in the light of the $W r / V r$ analysis (fig. 2), " $b$ " is broken down to,

" $b_{1}$ ", mean dominance,

" $b_{2}$ ", additional effects due to dominant genes restricted to certain of the parental lines,

" $b_{3}$ ", residual dominance effects.

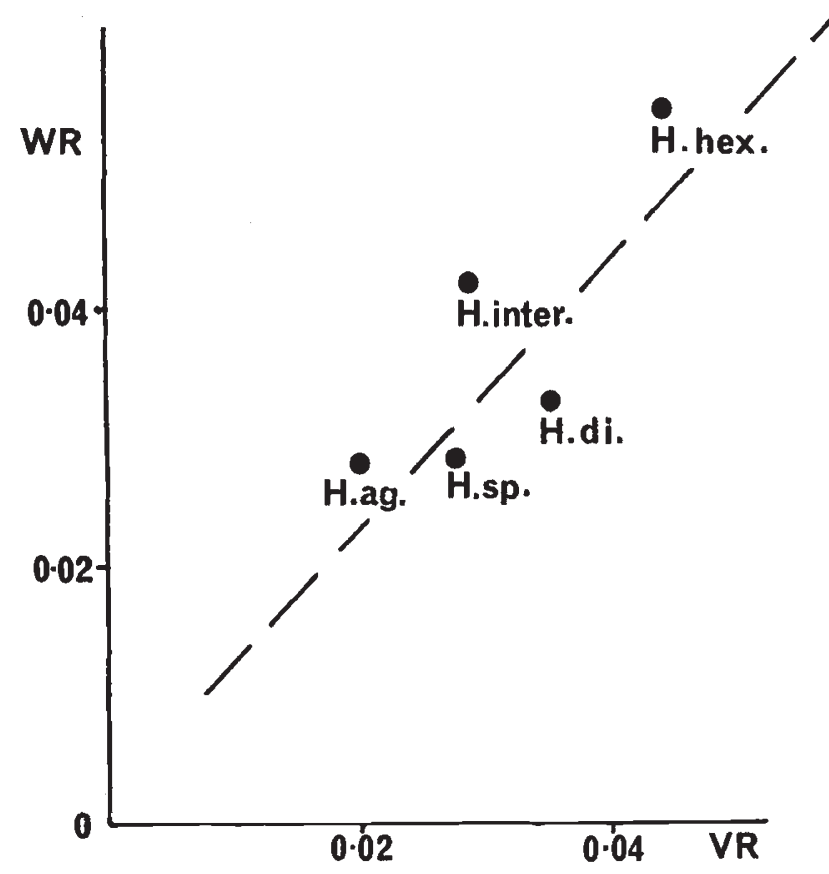

Fig. 2. - The array covariance $(W r)$ plotted against the array variance $(V r)$ for parent and $F_{1}$ chiasma frequencies.

The tables show,

(a) A highly significant " $a$ " item for both $\mathrm{F}_{1}$ and $\mathrm{F}_{2}$ generations $(P=<0.001)$, testifying to a control exercised by genes with additive effects.

(b) " $b$ " to be just significant at the 5 per cent. level in the $F_{1}$ analysis, approaching significance in the $F_{2}$ analysis $(P=0 \cdot 10-0 \cdot 05)$. The conclusion is that genes with non-additive effects play a smaller part in controlling the chiasma frequency.

The $\mathrm{F}_{1}$ analysis also shows that " $b_{2}$ " contributes most to the " $b$ " sum of squares. Table 4 indicates that this is due to genes carried by $H$. agriocrithon, which has the highest chiasma frequency, showing dominance throughout the array. Although such dominance effects are not widespread or pronounced in the $F_{1}$ there is enough to justify further analysis by the $W r / V r$ method of Jinks (1954).

$W r / V r$ analysis. The array covariances are plotted against the array variances in fig. 2. Bearing in mind the small number of lines involved, 
the regression, although not quite significant at the 5 per cent. level, tends to confirm the dominance effects inferred from the analysis in table 4 . The positions of the points along the regression line confirm, also, the direction of dominance to be towards a high chiasma frequency with $H$. agriocrithon, the species with the highest frequency, nearest to the origin and, furthest away, $H$. hexastichum, the species with the lowest chiasma frequency.

To summarise, the analyses show that the variation is controlled mainly by genes with additive effects and, to a lesser extent, by genes with nonadditive effects. A significant component of the non-additive variation is attributable to genes displaying normal dominance.

These findings, coupled with the continuous nature of the variation displayed (fig. 1), are readily interpreted as a reflection of control by many genes, comprising possibly a classical polygenic system made up of factors with small, similar and supplementary effects (Mather, 1949). In the following section are set out the results of a scheme devised to locate by assay the genes involved.

\section{(iii) The Chromosome Assay}

As with previous assays (Mather and Harrison, 1949; Breese and Mather, 1957, 1960; Thoday, 1961, 1966) the procedure was, first, to pick out, with the aid of marker genes, the chromosomes whose genic activity contribute substantially towards the chiasma frequency variation and, subsequently, to explore in more detail the sites of activity within these chromosomes. As compared with Drosophila the barley complement is crudely marked and the assay, in consequence, that much cruder.

\section{(a) The Complement}

Gene markers controlling the 11 characters listed under Materials and Methods cover six out of the haploid set of seven chromosomes. An initial survey took into account the first nine characters in this list. Correlations were sought between their segretation and that of chiasma frequencies in $F_{2}$ progenies. Of the nine characters used only one, kernel row number, was correlated with the chiasma frequency. Control of this character depends on at least one gene located in chromosome 2. On the assumption that the correlations may reflect a "concentration" of chiasma frequency genes in chromosome 2 two more characters marking that chromosome, awn length and internode length, were surveyed. These two, in addition to kernel row number and height, which was also included in the initial survey, provide a means not only for confirming that genes influencing chiasma frequency are found in chromosome 2. They may be used to indicate where, within that chromosome, such genes are located. Details of the correlations between markers and chiasma frequency are given below.

\section{(i) Kernel Row Number}

\section{(b) Chromosome 2}

It will be recalled that two types of segregation were found in the $F_{2}$ families from crosses between two- and six-rowed parents. Crosses with $H$. agriocrithon as the six-row parent gave segregations indicating control by two genes. One of the genes is on chromosome 2. The location of the second gene is not known. 
In table 6 are the mean chiasma frequencies for the different segregating phenotypes in the only two $\mathrm{F}_{2}$ families providing at the same time sufficient data and, as well, being derived from parents differing both in chiasma frequency and kernel row number. Both " $a$ " and " $b$ " are $\mathrm{F}_{2}$ 's from crosses between high chiasma frequency/six-rowed and low chiasma frequency/tworowed parents. Because the genes for high chiasma frequency carried by

TABLE 6

The mean chiasma frequencies of two-row and non-two-row segregates in two $F_{\mathrm{g}}$ families

$\begin{array}{ccc}\mathrm{F}_{2} \text { cross } & \text { Two-rowed } & \text { Non-two-rowed } \\ \text { ocrithon } \times \text { H. spontaneum } & 14.43 & 14.90 \\ & 14.95 & 15.45 \\ \text { ocrithon } \times \text { H. distichum } & 14.69 & 15.18\end{array}$

H. agriocrithon are dominant we should expect, if there is linkage between kernel row number and chiasma frequency, the two-rowed segregates to have a lower mean chiasma frequency. An analysis of variance confirms this $(P=0 \cdot 05-0 \cdot 01)$. This evidence provided the first, albeit tenuous, indication of a possible linkage between genes influencing chiasma frequency with a marker gene in chromosome 2.

Awn length : Chiasmata

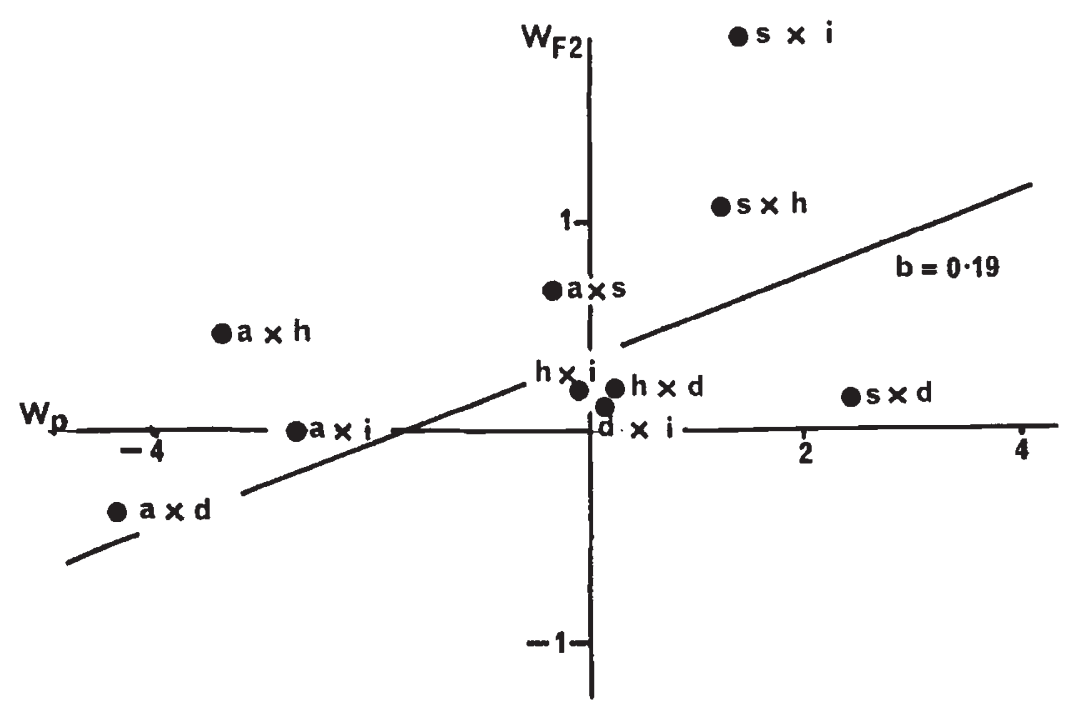

FiG. 3.-Mean awn length plotted against the mean chiasma frequency for parents, indicated by the appropriate initial letters, and for individual $F_{2}$ plants derived from these parents.

(ii) Awn length and chiasma frequency

Although the segregation results in a mainly discontinuous variation in $F_{2}$ it will be recalled that, due to the difficulty of distinguishing between short awn $(l k / l k)$ and intermediate $(L k / l k)$ phenotypes, awn length was treated as a continuous variable, no attempt being made to "split " the $F_{2}$ progenies into the three discrete classes. 
The awn length is plotted against the chiasma frequency for individual plants in all segregating $\mathrm{F}_{2}$ families in fig. 3. Also plotted are the means for awn length and chiasma frequency in the parent phenotypes. The graphs show that, in general, the awn length/chiasma frequency relationship in each $F_{2}$ is similar to that displayed by the two parents. For example, where

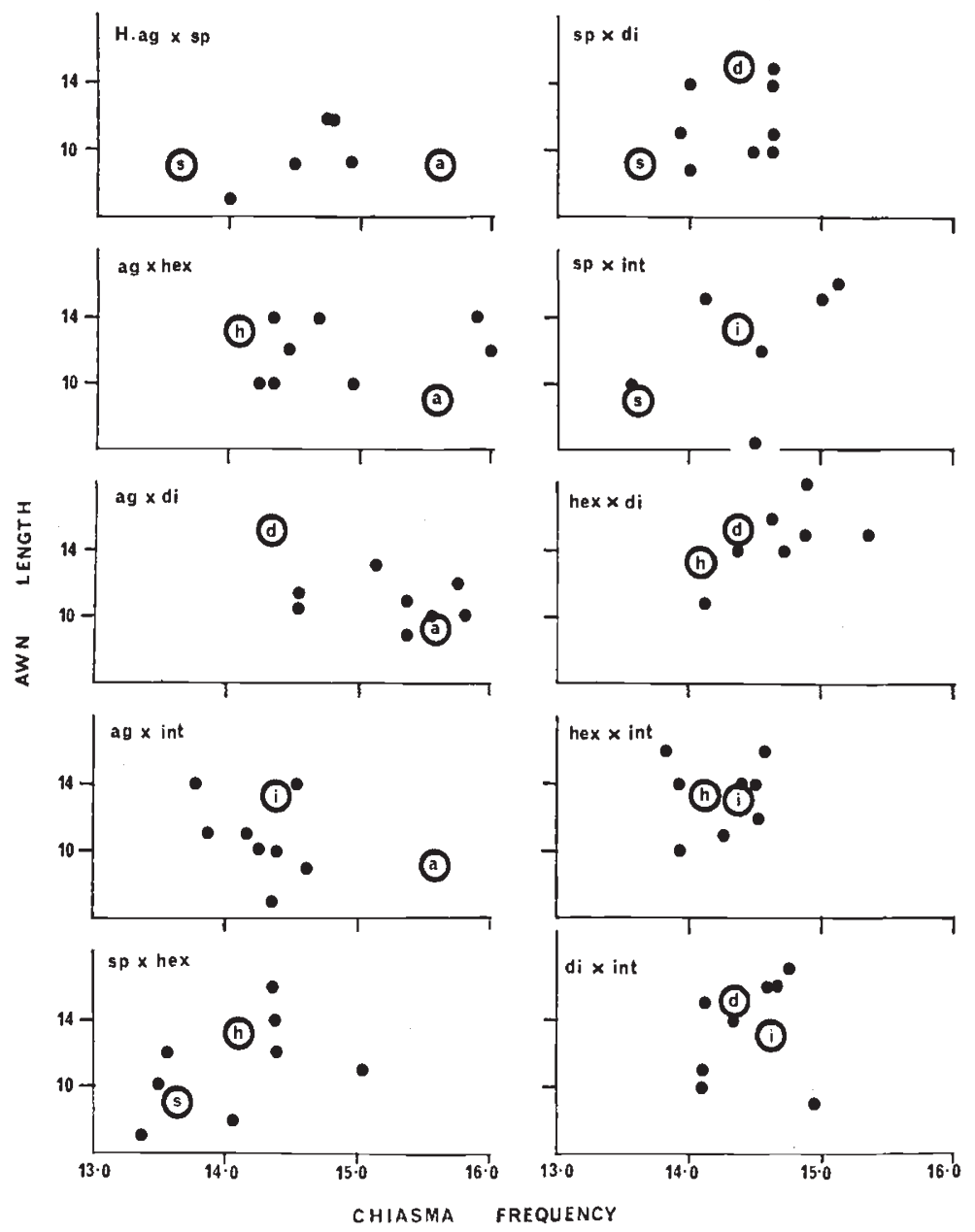

FIG. 4.-The covariance of awn length on to chiasma frequency for the $F_{2}\left(W_{\mathrm{F} 2}\right)$ plotted against the parental covariance $\left(W_{p}\right)$.

the combination of characters in the parents is high chiasma frequency/long awns and low chiasma frequency/short awns then awn lengths among the $\mathrm{F}_{2}$ tend to increase with increasing chiasma frequency. In order to test the significance of the parental and $\mathrm{F}_{2}$ correlations the method adopted was to compare the covariance of awn length on to chiasma frequency in each $\mathrm{F}_{\mathbf{2}}$ with that of the parental covariance. The parental covariance is $W_{p}=$ $\Sigma P x y$, where $x$ and $y$ are the mean parental values for the two characters, and the $\mathrm{F}_{2}$ covariance is $W \mathrm{~F}_{2}=\frac{\Sigma P x^{\prime} y^{\prime}}{n-1}$ where $x^{\prime}$ and $y^{\prime}$ are the values for the 
two characters in individuals of the $\mathrm{F}_{2}$ family, $n$ being the number of individuals in that family. The covariances are presented in fig. 4. An analysis of variance shows that $W_{p} / W_{\mathrm{F}_{2}}$ gives a linear regression significant at the 5 per cent. level. In this analysis the probability value was halved because the $W_{p} / W_{\mathrm{F}_{2}}$ relationship is on a priori grounds expected to be positive.

(iii) Spike internode length (Spike density)

Tests for correlations betwen chiasma frequency and internode length in $\mathrm{F}_{2}$ are of the parent covariance $/ \mathrm{F}_{2}$ covariance type described above. Internode

\section{Internode length : Chiasmata}

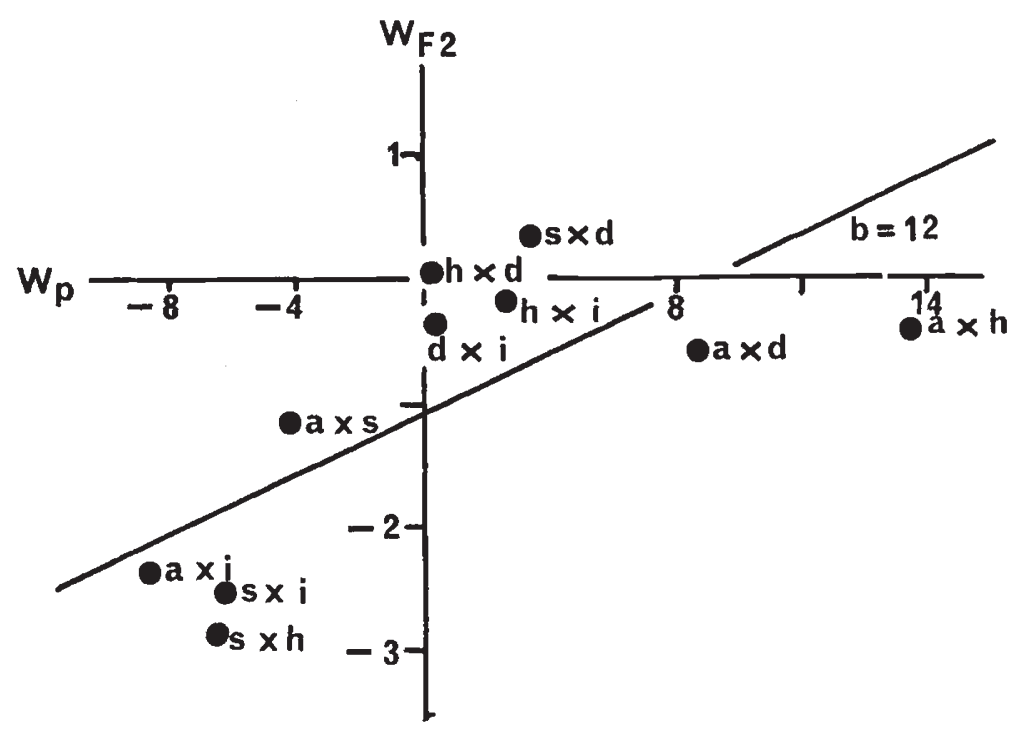

Fig. 5.-Mean internode length plotted against the mean chiasma frequency for parents and for individual $F_{2}$ plants.

length, like awn length, has been treated as a continuous variable with no attempt at sub-division into arbitrary classes. The internode lengths for parents and $\mathrm{F}_{2}$ 's are plotted in fig. 5 . In figure 6 are the $\mathrm{F}_{2}$ covariances plotted against the parental covariances. On the expectation of a positive slope the regression is significant at the 2 per cent. level.

The correlations between the expression of kernel row number, awn length and of spike internode length with chiasma frequency among parental and $\mathrm{F}_{2}$ phenotypes together provide very strong evidence for linkage between genes controlling chiasma frequency and genes on chromosome 2. In contrast, there was no indication of a linkage between chiasma genes and the other marker on chromosome 2, namely plant height.

\section{(c) Linkage between the markers}

Before concluding that genes controlling the chiasma frequency at meiosis are located in chromosome 2 it is first necessary to confirm that the three characters correlated with chiasma frequency are linked with one 
another as would be expected from the previous reports showing all three to be controlled by genes in chromosome 2. The following "linkage tests" were carried out.

1. Between kernel row number and awn length.

2. Between kernel row number and internode length.

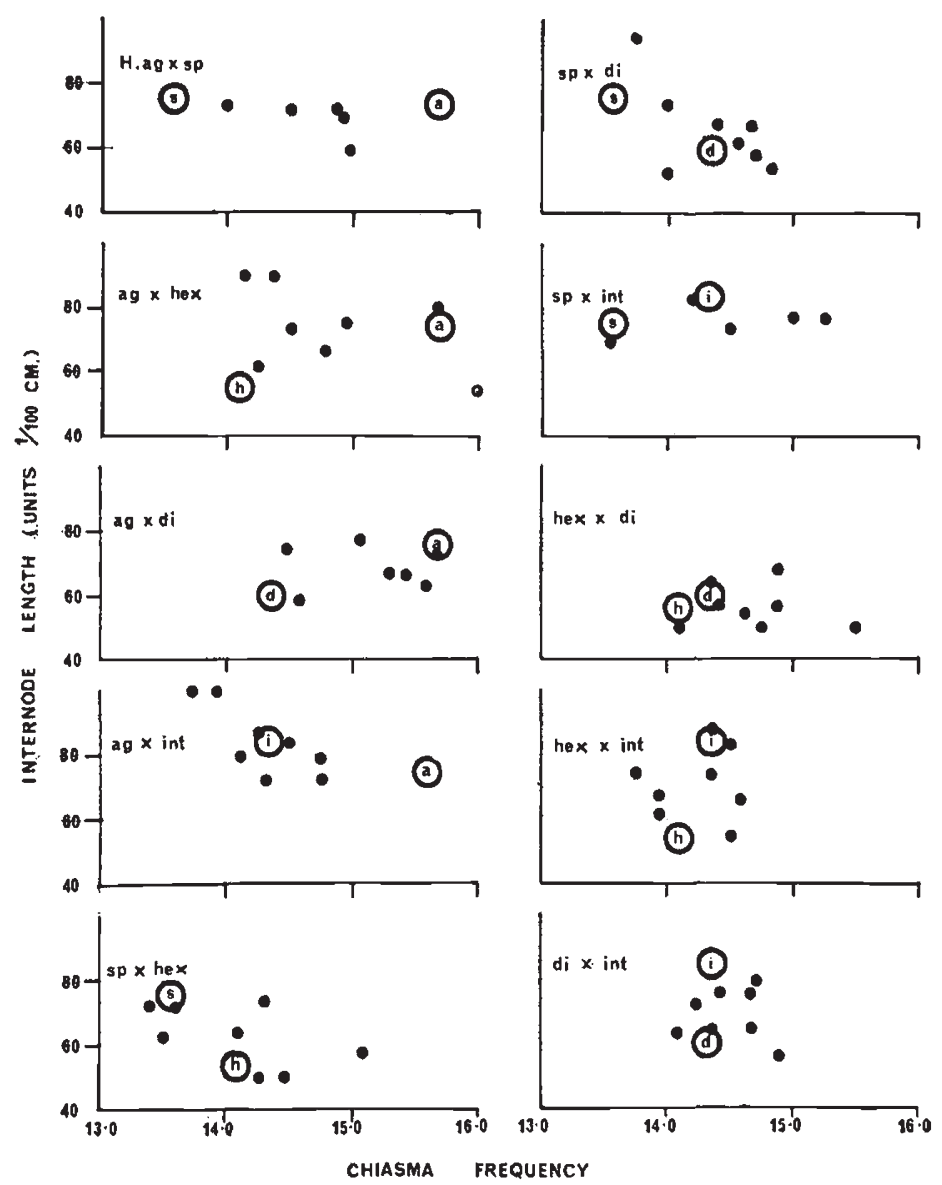

Fig. 6.-The covariance of internode length on to chiasma frequency for the $\mathrm{F}_{2}$ ( $W_{\mathrm{F}_{2}}$ plotted against the parental covariance $\left(W_{p}\right)$.

(i) Kernel row number/awn length

Only three families segregate in respect of both characters. Two of these (table 7) are from crosses between six-rowed parents with " short" awns, and two-rowed parents with "long" awns. In the $F_{2}$ 's the two characters are associated in the same combination as in the parents i.e. increasing awn length with decreasing kernel row number. The association or correlation of characters is significant $(P=<0.001$ and $P=<0.03$, table 7). The probabilities are halved because the expectation in $F_{2}$ is for the same combination of characters as was shown by the parent.

In the third cross, between $H$. hexastichum and $H$. spontaneum, the correlations were not significant. 
The significant correlations between kernel row number and awn length in two of the three families, however, is good confirmation of the expected linkage between their determinants.

\section{TABLE 7}

Awn length and kernel row number in parents and $F_{2}$ progenies

(a) H. agriocrithon (six-rowed with short awns-- $8.3 \mathrm{~cm}$.) $\times H$. distichum (two-rowed with long awns $-15 \cdot 0 \mathrm{~cm}$.)

$\begin{array}{cccc}\text { Awn length (cm.) } & \text { Two-rowed } & \text { Intermediate } & \text { Six-rowed } \\ 6 & - & 1 & - \\ 8 & - & 2 & 1 \\ 10 & 5 & 7 & 1 \\ 12 & 7 & 5 & - \\ 14 & 3 & 2 & - \\ 16 & 4 & - & - \\ 18 & 1 & - & - \\ 20 & - & - & - \\ 22 & 1 & - & - \\ \text { Total } & 21 & 17 & 2\end{array}$

Correlation coefficient $\left(r_{38}\right)=0.50(\mathrm{P}=<0.001)$.

(b) H. hexastichum (six-rowed with relatively short awns-13 cm.) $\times H$. distichum (two-rowed with long awns $-15 \mathrm{~cm}$.)

Awn length (cm.) Two-rowed Intermediate Six-rowed

$\begin{array}{cccc}6 & - & - & 2 \\ 8 & - & 1 & 1 \\ 10 & - & 2 & 1 \\ 12 & 4 & 2 & 1 \\ 14 & 5 & 4 & 5 \\ 16 & 2 & 3 & - \\ 18 & 2 & 2 & 1 \\ 20 & 1 & - & - \\ 22 & - & 1 & - \\ \text { Total } & 14 & 15 & 11\end{array}$

Correlation coefficient $\left(r_{38}\right)=0.30(\mathrm{P}=<0.03)$.

(ii) Kernel row number and internode length

Linkage is nicely demonstrated by using the parent/ $F_{2}$ covariance analysis described in the previous section. The covariances of internode length on kernel row number in $\mathrm{F}_{2}\left(W_{\mathrm{F}_{2}}\right)$ are plotted against the parent covariances $\left(W_{p}\right)$ in fig. 7 for the four families segregating in respect of both characters. A positive regression is evident, and significant $(P=<0.03)$.

The two tests above serve to confirm that all three characters are represented by markers on the same chromosome (chromosome 2) as had been previously reported.

\section{(d) The possibility of pleiotropy}

While the correlations demonstrated between chiasma frequency and the three morphological characters are compatible with linkage between their determinants they could be attributed to another cause, namely pleiotropy. That genes controlling each of the three morphological characters would, as well, have pleiotropic effects on chiasma frequency is extremely unlikely. 
It is ruled out completely on the grounds that the chiasma frequency of the parental subspecies is quite independent of morphology. For example, both $H$. agriocrithon and $H$. spontaneium display short awns. The former, however, has a high, the latter a low, chiasma frequency.

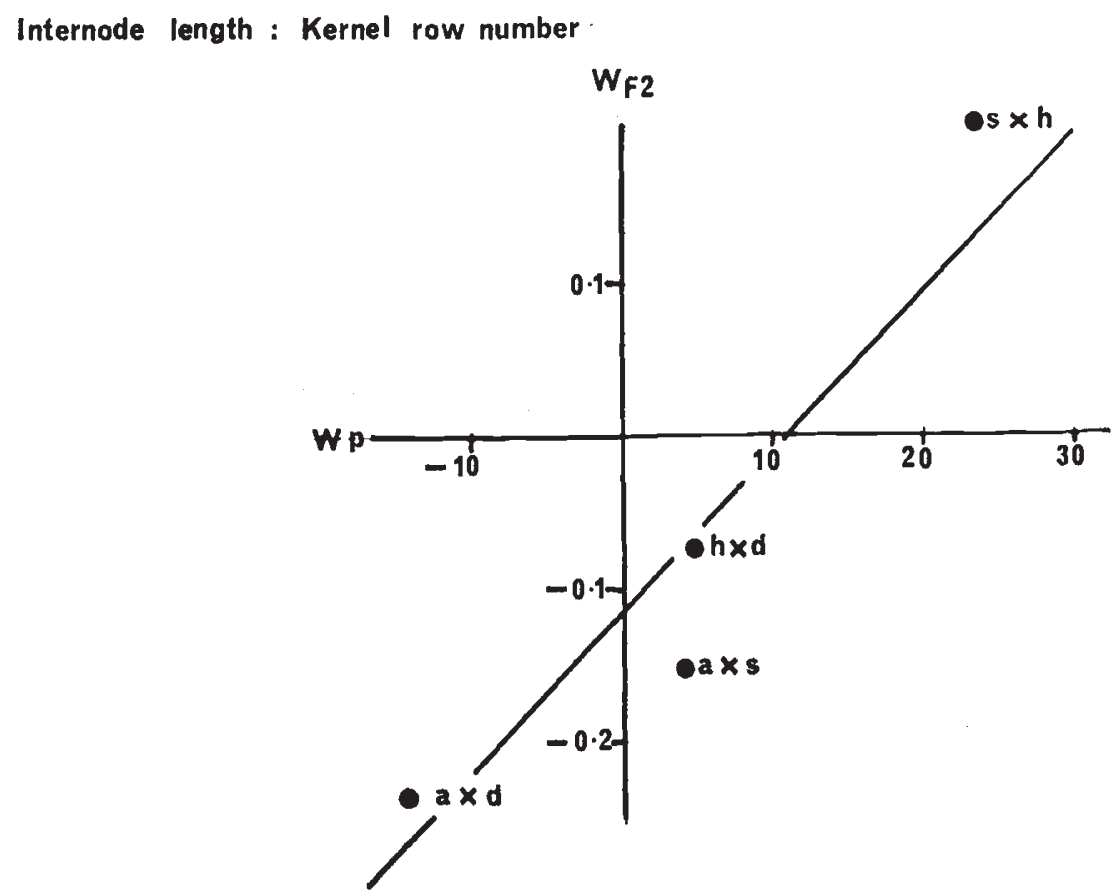

Frg. 7.-The covariance of internode length on kernel row number in $\mathrm{F}_{2}\left(W_{\mathrm{F} 2}\right)$ plotted against the parental covariance $\left(W_{p}\right)$ for the four $F_{2}$ families segregating for both characters.

\section{(e) The distribution of markers in chromosome 2}

Having disposed of pleiotropy and established therefore that genes controlling chiasma frequency are concentrated in chromosome 2 it is worthwhile trying to find out where on this chromosome they are located. Genes controlling awn lengths ( $L k / l k)$, spike internode length ( Rin/rin) and kernel row number $(V / v)$ have been mapped in the long arm, covering a distance of not more than 40 units (Litzenburger and Green, 1951; Woodward, 1957). The gene affecting height $(H / h)$ has been mapped outside the region spanned by rin and $v$. It will be recalled that there was no suggestion of linkage between chiasma frequency and plant height. It is possible that the concentration of genes influencing chiasma frequency in chromosome 2 are located, at least mainly, within the region v-rin in the long arm.

(f) A measure of the activity of genes on chromosome 2 affecting chiasma frequency

If genes controlling the variation in chiasma frequency were distributed uniformly throughout the Hordeum complement, each of the seven chromosomes would contribute a one-seventh share to the control of the variation. To detect a correlation between chiasma frequency and markers on a particular chromosome does not in itself, therefore, argue for a " concentra- 
tion " of chiasma genes in that chromosome. The establishment of the correlation, i.e. of linkage, in one chromosome and not in others could reflect more upon the effective marking of that chromosome rather than upon a "concentration" of chiasma frequency genes. The assumption implicit throughout this paper that the linkage, in chromosome 2, is evidence for a "concentration" of chiasma genes in that chromosome is only justified therefore if it can be shown that genes on chromosome 2 contribute disproportionately more than do genes on other chromosomes to the chiasma variation.

In the present work one of the best of the markers in chromosome 2, indeed in the whole complement, is awn length. Although it is difficult to distinguish intermediate $(L k / l k)$ from short awned phenotypes $(l k / l k)$ it is possible with reasonable confidence to classify the $F_{2}$ families into "shorts" $(L k / l k$ and $l k / l k)$ and "longs". This facility permits of a rough assessment of the extent to which chromosome 2 contributes to the chiasma frequency variation.

$H$. spontaneum crosses. The chiasma frequencies of "short" and "long" awned $\mathrm{F}_{2}$ progenies from crosses involving $H$. spontaneum are given in table 8 . $H$. spontaneum has short awns and a low chiasma frequency. As expected the short awned $F_{2}$ plants have a lower chiasma frequency than the long awned. The difference amounts to 0.43 chiasmata. 0.43 chiasmata represents 64 per cent. of the difference between the chiasma frequency of the parents, i.e. between $H$. spontaneum (13.62) and the other three species (14.29). Because the $L k / l k$ and $l k / l k$ genotypes have been combined in this analysis the value is likely to be an underestimate of the contribution to the chiasma variation of genes on chromosome 2 linked to $l k$. Whether or not this is so there would appear to be no doubt that genes linked to $l k$ on chromosome 2 contribute disproportionately to the chiasma frequency variation.

Crosses involving $H$. agriocrithon. $H$. agriocrithon has short awns and a relatively high chiasma frequency $(15 \cdot 64)$. As expected the long awned $F_{2}$ plants have the lower chiasma frequencies, 14.41 as compared with 14.91 for the "short" $(L k / l k$ and $l k / l k)$. The difference between the classes, 0.50 chiasmata, represents 37 per cent. of the difference in the chiasma frequency of $H$. agriocrithon $(15 \cdot 64)$ as compared with the other parents $(14 \cdot 29)$.

In neither of the above comparisons are the data extensive enough nor precise enough to lend anything approaching accuracy to the estimates of variation attributable to chromosome 2. Together they do provide, however, firm grounds for concluding a large contribution by chromosome 2, a " concentration" of activity affecting chiasma frequency in that chromosome.

\section{Discussion}

That differences in chiasma frequencies between subspecies are genotypically controlled is not surprising. It is not clear what adaptive role, if any, they play in this instance because the subspecies are all strict inbreeders. Consequently differences in chiasma frequencies, other than very low frequencies causing chromosome loss and infertility, can have no relevance to adjustments in the amount of genetic recombination. It may be that the differences are relicts of an adaptive variation in genetic recombination between outbreeding ancestors.

Of greater interest is the information gained about the control of the 
TABLE 8

The chiasma frequencies of " short" ( $\mathrm{Lk} / \mathrm{lk}$ and $\mathrm{lk} / \mathrm{lk}$ ) and "long" awned ( $\mathrm{Lk} / \mathrm{Lk}$ ) plants in $F_{2}$ 's derived from (a) H. spontaneum and, (b) H. agriocrithon. crosses

(a)

\begin{tabular}{cc} 
“Shorts" & "Longs " \\
$13 \cdot 40$ & $14 \cdot 30$ \\
$14 \cdot 30$ & $14 \cdot 60$ \\
$14 \cdot 10$ & $14 \cdot 70$ \\
$15 \cdot 05$ & $14 \cdot 05$ \\
$13 \cdot 50$ & $15 \cdot 20$ \\
$14 \cdot 35$ & $15 \cdot 00$ \\
$13 \cdot 65$ & $14 \cdot 20$ \\
$14 \cdot 70$ & \\
$13 \cdot 95$ & \\
$14 \cdot 65$ & \\
$14 \cdot 05$ & \\
$14 \cdot 40$ & \\
$14 \cdot 55$ & \\
$13 \cdot 55$ & \\
\hline $14 \cdot 15$ & \\
\hline
\end{tabular}

Data pooled from $H$. spontaneum $\times H$. hexastichum $\times H$. distichum $\times H$. intermedium.

(b)

\begin{tabular}{lc} 
"Shorts" & "Longs " \\
$16 \cdot 00$ & $14 \cdot 45$ \\
$14 \cdot 40$ & $15 \cdot 15$ \\
$14 \cdot 95$ & $13 \cdot 85$ \\
$14 \cdot 30$ & $14 \cdot 20$ \\
$14 \cdot 70$ & \\
$15 \cdot 80$ & \\
$15 \cdot 30$ & \\
$15 \cdot 35$ & \\
$15 \cdot 55$ & \\
$15 \cdot 85$ & \\
$14 \cdot 60$ & \\
$15 \cdot 80$ & \\
$14 \cdot 60$ & \\
$14 \cdot 60$ & \\
$14 \cdot 25$ & \\
$14 \cdot 30$ & \\
$14 \cdot 65$ & \\
$13 \cdot 90$ & \\
$14 \cdot 30$ & \\
14.91 & \\
\hline
\end{tabular}

Data from $H$. agriocrithon $\times H$. hexastichum

$$
\begin{aligned}
& \times H . \text { distichum } \\
& \times H \text {. intermedium. }
\end{aligned}
$$

chiasma frequency. It exhibits a continuous variation in heredity such as would arise by polygenic control, exercised mainly through genes with additive effects but partly, also, through genes with non-additive action including dominance. The dominance is in the direction of higher chiasma frequency, as in rye (Rees and Thompson, 1956; $c f$. Sun and Rees, 1964) 
and Drosophila (Lawrence, 1958, 1963; Law, 1961). The assay described provides further information on this controlling system. We appreciate, of course, that the information from the assay is nowhere near as precise as that familiar to us from assays in other organisms, namely Drosophila (e.g. Mather and Harrison, 1949; Breese and Mather, 1957; Thoday, 1966) and wheat (Law, 1967; Kempanna, 1963). Partly this is because the marking of the Hordeum complement was lacking in respect both of the number and quality of marker genes. Equally important, we had no means by which to " block" recombination and thereby maintain and manipulate intact the marked chromosomes in the way achieved, for example, by inversions in Drosophila. Our assay, in fact, was crude and approximate. Even so it does provide evidence for a "concentration" of genes controlling chiasma frequency in one particular chromosome, viz. chromosome 2. The "concentration" may be interpreted in one of two ways. Either there is a large cluster of polygenes in chromosome 2 which determines, in large part, the chiasma frequency or, else, one or few genes with major effect on chiasma frequency are located in this particular chromosome. As Mather (1949) points out a continuous variation, such as displayed by the chiasma frequencies in Hordeum, does not always reflect control of the classical polygenic type, namely by genes of small, equal and supplementary effect. Whether, in this present instance, it be a major gene or a cluster of polygenes that is involved it is interesting to note that Kempanna's assay of wheat chromosomes (1963) revealed a disproportionate influence upon the chiasma frequency variation of homoeologous chromosomes $3 \mathrm{~A}, 3 \mathrm{~B}$ and $3 \mathrm{D}$. It appears that in the two cereals one particular chromosome type is inordinately involved with control over the chiasma frequency.

Finally, the assay confirms the feasibility of dissecting and partitioning into manipulative components the genetic systems controlling some characters which display a continuous variation in heredity (Thoday, 1966).

\section{Summary}

1. Variation in chiasma frequency between Hordeum subspecies is controlled by genes with mainly additive effects. To a lesser extent control is exercised by genes with non-additive effects including dominance. High chiasma frequency is dominant to low.

2. The variation displayed is of a continuous nature. A chromosome assay revealed that a disproportionate contribution to the chiasma frequency variation is attributable to a gene, or to a cluster of genes, located in chromosome 2.

Acknowledgments.-We are grateful to Dr A. Durrant for advice on statistical matters and to Dr E. L. Breese for helpful comments on the manuscript. One of us (M. D. B.) gratefully acknowledges the award of an A.R.C. postgraduate studentship.

\section{REFERENCES}

Åberg, E. 1940. Taxonomy and phylogeny of Hordeum L. Sect. Cerealia Ands. Symb. Bot. Upsaliens, 4(2), 1.

ANDERSEN, W. R. 1958. Linkage relationships of located and unlocated genetic testers in certain normal and translocation stocks of barley. M.Sc. Thesis. Utah State Univ. (Reviewed in Nilan, 1964).

AZIz, M. A., AND MIR, A. R. 1960. Inheritance studies in cereals. II. Inheritance of awn characters in barley. Proc. 12th Pakistan Sci. Conf., Hyderabad. (Abst.). P.B.A. XXXIII (1044).

$2 \mathrm{D} 2$ 
BELL, G. D. H. 1965. The phylogeny of temperate cereals. Essays on crop plant evolution, pp. 70-102. Camb. Univ. Press.

BREESE, E. L., AND MATHER, K. 1957. The organisation of polygenic activity within a chromosome in Drosophila. I. Hair characters. Heredity, 11, 373-395.

BREESE, E. L., AND MATHER, K. 1960. The organisation of polygenic activity within a chromosome in Drosophila. II. Viability. Heredity, 14, 375-399.

DAS, K. 1957. Partial sterility in a line of X-ray irradiated barley. Ind. J. Genet. Plant Breeding, 17, 58-64.

DONEY, D. L. 1961. An inheritance and linkage study of barley with special emphasis on purple pigmentation of the aurical. (Abst.). P.B.A. XXXIV, 4042.

DowRICK, G. J. 1957. The influence of temperature on meiosis. Heredity, 11, 37-49.

HAYES, J. D., AND RANA, M. s. 1966. Genetic resistance to DDT in Hordeum. I. Linkage studies in diploid barley. Heredity, 21, 581-595.

HAYMAN, B. I. 1954. The analysis of variance of diallel tables. Biometrics, 10, 235-244.

HENDERSON, s. A. 1962. Temperature and chiasma formation in Schistocerca gregaria. II. Cytological effects at $40^{\circ} \mathrm{C}$. and the mechanism of heat-induced univalence. Chromosoma, $16,192-221$.

JINKs, J. L. 1954. The analysis of quantitative inheritance in a diallel cross of Nicotania rustica varieties. Genetics, 39, 767-788.

JoGr, B. s. 1956. The heritability of agronomic and disease reaction characteristics in two barley crosses. Agron. F., 48, 293-296.

KEMPANNA, c. 1963. Investigations into the genetic regulation of meiotic chromosome behaviour in Triticum aestivum. Ph.D. Thesis. Univ. Cambridge.

LAw, C. N. 1961. Recombination in the X-chromosome of Drosophila melanogaster. Nature Lond., 191, 1180-1181.

LAW, c. N. 1963. An effect of potassium on chiasma frequency and recombination. Genetica, $33,313-329$.

LAw, c. N. 1967. The location of genetic factors controlling a number of quantitative characters in wheat. Genetics, 56, 445-461.

LAWRENCE, M. J. 1958. Genotypic control of crossing-over on the first chromosome of Drosophila melanogaster. Nature (London), 182.

LAWRENCE, M. J. 1963. Control of crossing-over in the $\mathrm{X}$ chromosome of Drosophila melanogaster. Heredity, 18, 27-46.

LITZENBURGER, s. C., AND GREEN, J. M. 1951. Inheritances of awns in barley. Agron. F., 43, 117-123.

ManN, H. O. 1953. Height inheritance in barley. M.Sc. Thesis. Colorado State Univ. (Reviewed in Nilan, 1964).

MATHER, K. 1949. Biometrical Genetics. Methuen, London.

MATHER, K., AND harrison, B. J. 1949. The manifold effect of selection. Heredity, 3, 1-52.

MORLEY-JONES, R. 1965. The analysis of variance of the half-diallel table. Heredity, 20, $117-121$.

MURTY, G. S., AND JAIN, K. B. L. 1960. Genetic studies in barley. II. Inheritance of fertility of the lateral florets and certain other characters. F. Indian Botan. Soc., 39, 281-308.

REES, H., AND THOMPSON, J. B. 1956. Genotypic control of chromosome behaviour in rye. III. Chiasma frequency in homozygotes and heterozygotes. Heredity, 10, 109-424.

SUN, S., AND REES, H. 1964. Genotypic control of chromosome behaviour in rye. VII. An adaptive heterozygote. Heredity, 19, 357-367.

TAKAHASHI, R. 1951. Studies on the classification and the geographical distribution of the Japanese barley varieties. II. Correlative inheritance of some quantitative characters with the ear types. Ber. Ohara Inst. Landwirtsch. Forsch., 9, 382-398.

TAKAHASHI, R. 1955. The origin and evolution of cultivated barley. Advances in Genetics, 7, 227-266.

TAKAKASHI, R., YAMAMOTO, J., YASUDA, s., AND ITANO, Y. 1953. Inheritance and linkage studies in barley. Ber. Ohara Inst. landwirtsch Forsch., 10, 29-52.

THODAY, J. M. 1961. Location of polygenes. Nature, 191, 368-370.

THODAY, J. M. 1966. New insights into continuous variation. Proc. 3rd International Congress of Human Genetics, 339-350.

WOODWARD, R. w. 1949. The inheritance of fertility in the lateral florets of the four barley groups. Agron. F., 41, 317-322.

woodward, R. w. 1957. Linkages in barley. Agron. J., 49, 28-32. 